\title{
Proning: Outcomes of Use of Force Followed With Prone Restraint
}

Daniel Lasoff', Christine A Hall², William P Bozeman ${ }^{3}$, Theodore C Chan ${ }^{4}$, Edward M Castillo4 and Gary M Vilke ${ }^{5 *}$

${ }^{1}$ University of Calgary, Canada

${ }^{2}$ Vancouver Island Health Research, Canada

${ }^{3}$ Wake Forest University, USA

${ }^{4}$ San Diego Medical Center, University of California, USA

${ }^{5}$ Department of Emergency Medicine, San Diego Medical Center, USA

\begin{abstract}
Background: EMS and police are often faced with violent subjects that require the use of force and the application of restraints. After gaining control and restraining subjects, he or she can be physically placed into a number of positions including prone, supine, on their side or sitting. However, due to cases of sudden death of restrained individuals, there has been increased scrutiny towards the positions in which a subject is left after he is restrained.
\end{abstract}

Methods: This was an evaluation of prospectively collected data from a single law enforcement agency for all subjects in which a use of force was utilized during a one year study period. Data collected includes whether the patient was agitated, resisting arrest, the level of resistance the subject demonstrated and how long the subject resisted for after being placed in his final restraining position.

Results: Of 2431 use of force incidents, $1535(63.1 \%)$ patients ended up being placed in a prone restraint position, $43(1.7 \%)$ were restrained lying face up, $64(2.7 \%)$ were placed on their sides and $224(9.2 \%)$ were placed in a sitting position. Of all of the subjects who were restrained, $1863(76.6 \%)$ incurred no injuries. $354(14.6 \%)$ subjects were treated at a hospital and then cleared for discharge. No fatalities were noted in any subjects of the research population.

Conclusion: Use of force incidents commonly result in individuals placed in a prone restraint position, however, we found no fatalities of individuals placed in a prone restraint position.

Keywords: Use of force; Restraint position; Proning; Restraint; Prone

\section{Introduction}

Emergency Medical Services (EMS) and police are often faced with violent subjects that require the use of force and the application of restraints. Many techniques are available to restrain patients including simple hand cuffing, to hobbling or hogtying or other manufactured devices. After gaining control and restraining the subject, the subject can be physically placed into a number of positions including prone, supine, on their side or sitting. Due to sudden deaths of individuals in police custody after restraint, there has been increased scrutiny towards the positions in which a subject is left after he is restrained, and it has been suggested that leaving a subject prone can be associated with increased risk for sudden death [1-7]. In fact, many law enforcement agencies and EMS systems have polices that do not allow for a restrained individual to be kept prone and must be placed in a "recovery position" on their side.

It has previously been reported that individuals who were placed in the prone position during police restraint were at risk for sudden death secondary to positional asphyxia [8-10]. Positional asphyxia has been described as respiratory compromise due to interference to the chest wall and diaphragm, impacting airway during sustained abnormal positioning of the body $[5,8,10,11]$. Since the 1980 's, several reports have been published that had implicated positional asphyxia as a cause of death for several individuals restrained in a prone or hogtie position [12,13]. Previous case reports and studies published by Reay and Stratton have attributed this to the inability to self-rescue due to restraints. Several more recent studies have evaluated physiological responses to healthy volunteers being placed in a proned position and having weight placed on the backs of volunteer's while proned $[14,15]$. Though most feel that proning is physiologically neutral, some individuals still question whether proning is a factor of sudden death for individuals in police custody as all of the research that demonstrates physiological neutrality were done in healthy research subjects [16]. Multiple studies have shown no deleterious physiological changes with proningand weight placed on one's back, however, to date, only one other study has prospectively evaluated outcomes of real world subjects in a field setting restrained in a proned position [17-19].

We sought to prospectively evaluate outcomes in subjects who were placed in the prone position during use of force incidents in San Diego County.

\section{Methods}

This was an evaluation of prospectively collected data from a single law enforcement agency, the San Diego Sheriff's Organization (SDSO). All subjects in which a Use of Force (UOF), defined as any physical contact during arrest that involved more than a simple joint lock application by sheriff's department officers or deputies during the calendar year 2009 were evaluated. When UOF was utilized, the involved officer completed a standardized data collection tool.

Data were collected from all UOF events during 2009 in San Diego and the method of restraint utilized, including handcuffs, hobble, leg core cuffs and neck restraint were documented as well as final resting

*Corresponding author: Vilke GM, Department of Emergency Medicine, San Diego Medical Center, California, USA, Tel: 6195436463; Fax: 6195433115; E-mail: gmvilke@ucsd.edu

Received June 14, 2017; Accepted June 27, 2017; Published July 04, 2017

Citation: Lasoff D, Hall CA, Bozeman WP, Chan TC, Castillo EM, et al. (2017) Proning: Outcomes of Use of Force Followed With Prone Restraint. J Forensic Med 2: 119. doi: 10.4172/2472-1026.1000119

Copyright: ( $\odot 2017$ Lasoff D, et al. This is an open-access article distributed under the terms of the Creative Commons Attribution License, which permits unrestricted use, distribution, and reproduction in any medium, provided the original author and source are credited. 
position. After each UOF event, the arresting officer would be required to submit a data collection form. Data collected included whether the subject was agitated, resisting arrest, the level of resistance the subject demonstrated and how long the subject resisted for after being placed in his final restraining position. Documentation also included whether or not the subject and any deputies were injured and if so what was the extent of the treatment were noted. Characteristics of the subject were also reported such as perceived intoxication, substance use or mental illness.

\section{Study location and population}

The SDSO sworn staff operate in the field setting covering approximately 4200 square miles with a population in San Diego County of 3.2 million people. The SDSO also operates in the County's six jail detention facilities that collectively have an average daily census in excess of 5000 inmates and over 100,000 bookings a year. The SDSO employs approximately 4200 staff of which 1200 are assigned to the law enforcement bureau and respond to over 200,000 911 calls annually and another half million that are non-emergency.

\section{Human subject's approval}

Human subjects' committee approval was obtained at the University of California, San Diego Human Research Protection Program.

\section{Statistics}

Data were entered into a database and spreadsheet (Access, Microsoft Corporation, Redmond, WA). Descriptive analysis was performed and observed proportions were determined with standard methods.

\section{Results}

Over the twelve-month study period, the SDSO had 524,427 documented subject encounters, of which 2431 (0.0046\%) resulted in UOF being utilized [20]. In our population, 1934 (79.6\%) subjects were males with a median age of 28 years. Of these subjects, 1079 (44.3\%) appeared to be under the influence of alcohol or drugs per arresting officer. Three hundred forty seven (14.3\%) appeared to be mentally impaired per arresting officers. Of the subject population, 2287 (94\%) were unarmed at time of arrest. Fifty subjects were armed with a gun, 55 with a knife/blade and other weapons included bats, sticks, objects present on scene.

Differing levels of intensity in UOF included 1513 episodes of empty hand control actions such as grabbing/pushing, restraining holds, pressure points and striking. There were 1137 episodes of using tools or devices such as oleoresin capsicum (OC) agents, impact weapons, and canines. There were 299 episodes of less lethal weapons such as pepper bell launchers, TASER electronic control devices, 12 gauge super sock and NOVA shield. Numerous encounters required more than one type of UOF action. In these 2431 UOF events, 1808 initial uses of force were effective. Six hundred fifty two subjects required a second method of force.

Of these UOF incidents, 1535 (63.1\%) patients ended up being placed in a prone restraint position, $43(1.7 \%)$ were restrained lying face up, $64(2.7 \%)$ were placed on their sides and 224 (9.2\%) were placed in a sitting position. Of all of the subjects who were restrained, 1863 (76.6\%) incurred no injuries. Three hundred fifty four (14.6\%) subjects were treated at a hospital and then cleared for discharge. Two hundred eight (8.6\%) subjects required hospitalization. No fatalities were noted in any subjects of the research population.

\section{Discussion}

A number of theories have been put forward as being responsible for the deaths in subjects placed in the prone position including underlying heart disease, obesity, respiratory disease, drug and alcohol toxicity and positional asphyxia. To date there have been numerous case reports of patients suffering sudden death while restrained [2-5]. Prone and hogtie positions were previously described as high risk $[4,5]$. Though subsequent research has since debunked the original work published by Reay, leading to the determination that the prone position is physiologically neutral with respect to ventilation $[8,15,17,18]$. Previous studies have even evaluated pulmonary function in individuals placed in a prone position and with up to $100 \mathrm{~kg}$ of weight on their backs [18]. These studies have shown no clinically significant changes in an individual's respiratory status. But criticisms have been that these are volunteers and do not reflect real world scenarios where subjects may be have been using drugs, alcohol or been involved in physical altercations prior to being restrained [21].

One similar study had been conducted in Canada to date. This was another prospective study which showed $42.8 \%$ of a subject set of 1255 subjects placed in a prone position without a single fatality. During that study, only one subject suffered a fatality and that subject was in a nonprone position. Our findings are similar in that there was not a single fatality and the Hall study also showed a profoundly low rate of sudden death for individuals in police custody after UOF incidents in general (1/1255). The incidence of sudden death is extremely low when looking at all police encounters and even in the subgroup of those who had UOF used against them.

\section{Study Limitations}

The data collected in this study were prospectively collected by the involved law enforcement officers and documented immediately after the event, however are subject to potential recall bias accuracies. Our study is likely to have been limited by the number of subjects enrolled. Because of the low rate of fatalities in our study, we were unable to statistically differentiate the rates of fatalities based on the modalities of restraint. However, our study does not seem to show an increased danger of the prone position in a restrained individual.

\section{Conclusion}

UOF incidents commonly result in individuals placed in a prone restraint position. Through our large population, we noted no fatalities of individuals placed in a prone restraint position. Likely there are numerous factors that place an individual in police custody at risk for sudden death including a history of mental illness, underlying heart disease, the presence of excited delirium syndrome and drug and alcohol intoxication. Future research should focus on high risk populations, including those suffering from drug intoxication, heart disease, obesity and chronic lung diseases.

\section{Acknowledgement}

The authors would like to thank the National Institute of Justice (Grant number 2006-DE-BX-K002) and the Canadian Police Research Centre (Contract \#W7714091131 (001/SQ) for the provision of unrestricted financial assistance for this project. This project could not have been successfully completed without the full participation and support deputies and administration of the San Diego Sheriff's Organization.

\section{References}

1. Pollanen MS, Chiasson DA Cairns JT, Young JG (1998) Unexpected death related to restraint for excited delirium: A retrospective study of deaths in police custody and in the community. Can Med Assoc J 158: 1603-1607.

2. Leigh A, Johnson G, Ingram A (1998) Deaths in police custody: Learning the lessons. Home Office Police Research Group. 
Citation: Lasoff D, Hall CA, Bozeman WP, Chan TC, Castillo EM, et al. (2017) Proning: Outcomes of Use of Force Followed With Prone Restraint. J Forensic Med 2: 119. doi: 10.4172/2472-1026.1000119

Page 3 of 3

3. Howard JD, Reay DT (1998) Positional asphyxia. Ann Emerg Med 32: 116-118.

4. Reay DT, Fligner CL, Stilwell AD, Arnold J (1992) Positional asphyxia during law enforcement transport. Am J Forensic Med Pathol 13: 90-97.

5. Stratton SJ, Rogers C, Green K (1995) Sudden death in individuals in hobble restraints during paramedic transport. Ann Emerg Med 25: 710-712.

6. O'Halloran RL, Frank JG (2000) Asphyxial death during prone restraint revisited: A report of 21 cases. Am J Forensic Med Pathol 21: 39-52.

7. Ross DL (1996) An analysis of in custody deaths and positional asphyxiation.

8. Reay DT, Howard JD, Fligner CL, Ward RJ (1998) Effects of positional restraint on oxygen saturation and heart rate following exercise. Am J Forensic Med Pathol 9: 16-18.

9. Hirsh CS (1994) Restraint asphyxiation. Am J Forensic Med Pathol 15: 266.

10. Reay DT, Howard JD (1999) Restraint position and positional asphyxia. Am J Forensic Med Pathol 20: 300-301.

11. Reay DT (1996) Suspect restraint and sudden death. FBI L Enforcement Bull 65: 22-25.

12. O'Halloran RL, Lewman LV (1993) Restraint asphyxiation in excited delirium. Am J Forensic Med Pathol 14: 289-295.
13. Morrison A, Sadler D (2001) Death of a psychiatric patient during physical restraint: Excited delirium-a case report. Med Sci Law 41: 46-50.

14. Chan TC, Vilke GM, Neuman T (1998) Reexamination of custody restraint position and positional asphyxia. Am J Forensic Med Pathol 19: 201-205.

15. Vilke GM, Chan TC, Neuman T, Clausen JL (2000) Spirometry in normal subjects in sitting, prone and supine positions. Respir Care 45: 407-410.

16. Laposata EA (1993) Positional asphyxia during law enforcement transport. Am J Forensic Med Pathol 14: 86-87.

17. Chan TC, Vilke GM, Neuman T (2000) Restraint position and positional asphyxia. Am J Forensic Med Pathol 21: 93

18. Chan TC, Neuman T, Clausen J, Eisele J, Vilke GM (2004) Weight force during prone restraint and respiratory function. Am J Forensic Med Pathol 25: 185-189.

19. Hall CA, McHale AM, Kader AS, Stewart LC, MacCarthy CS, et al. (2012) Incidence and outcome of prone positioning following police use of force in a prospective, consecutive cohort of subjects. J Forensic Leg Med 19: 83-89.

20. Gore WD (2012) Use of force/internal affairs statistical report. San Diego County Sheriff's Department.

21. Reay DT, Howard JD (1999) Restraint position and positional asphyxia. Am J Forensic Med Pathol 20: 300-301. 